\title{
RELIEF OF PRIMARY CERVICAL DYSTONIA SYMPTOMS BY LOW FREQUENCY TRANSCRANIAL MAGNETIC STIMULATION OF THE PREMOTOR CORTEX
}

\section{Case report}

\author{
Nasser Allam', Joaquim Pereira Brasil-Neto², Pedro Brandão3, \\ Fernanda Weiler ${ }^{3}$, Jairo de Barros Filho ${ }^{3}$, Carlos Tomaz ${ }^{4}$
}

\begin{abstract}
Objective: To evaluate the effect of low-frequency repetitive transcranial magnetic stimulation (rTMS) on the symptoms of a patient with primary segmental dystonia (PSD). Method: 1200 TMS pulses at a frequency of $1 \mathrm{~Hz}$, over the premotor cortex, with an intensity of $90 \%$ of the motor threshold (MT), using an eight-shaped coil; a total of 5 sessions were carried out. Results: A reduction of 50 percent in the neck subset of the Burke, Fahn and Marsden torsion dystonia scale (BFM) was observed in our patient. Conclusion: The reduction in the BFM scale supports the concept that rTMS of the premotor cortex may reduce specific motor symptoms in PSD.
\end{abstract}

KEY WORDS: segmental dystonia, premotor cortex, transcranial magnetic stimulation.

\begin{abstract}
Alívio da distonia cervical primária com o uso da estimulação magnética transcraniana de baixa freqüência sobre o córtex pré-motor: relato de caso

RESUMO - Objetivo: Investigar o efeito da estimulação magnética transcraniana repetitiva (EMTr) de baixa freqüência nos sintomas de um paciente com distonia segmentar primária (DSP). Método: 1200 pulsos a uma freqüência de $1 \mathrm{~Hz}$, sobre o córtex pré-motor, a uma intensidade de $90 \%$ do limiar motor (LM), usando uma bobina em forma de 8. Foram realizadas 5 sessões. Resultados: Uma redução de $50 \%$ no sub-item "pescoço" na escala de distonia de torção de Burke, Fahn e Marsden (BFM) foi observada no paciente em questão. Conclusão: A redução na escala BFM corrobora a idéia de que a EMTr sobre o córtex pré-motor pode reduzir sintomas motores específicos na DSP.
\end{abstract}

PALAVRAS-CHAVE: distonia segmentar, córtex pré-motor, estimulação magnética transcraniana.

Idiopathic cervical dystonia is defined as involuntary twisting and turning of the neck caused by sustained muscle contractions. Its most effective treatment is injecting overactive muscles with botulinum toxin type $\mathrm{A}$, inducing blockade of acetylcholine release at the neuromuscular junction. The only disadvantages of this therapy are its temporary effect and a lack of response in rare cases.

Eletrophysiological studies have shown shifts in motor cortex excitability of dystonic patients, in particular, a reduction in cortical inhibition, an excessive motor evoked potential facilitation and shorter cortical silent periods, leading to an increase in corticospinal motor output ${ }^{1-4}$. This dysfunction appears to be related to changes in the pattern of neuronal activity in the basal ganglia thalamocortical motor circuit, especially involving impaired gamma-aminobutyric acid (GABA) levels in the sensorimotor cortex and lentiform nuclei ${ }^{5}$. Repetitive transcranial magnetic stimulation (rTMS) can modulate cortical excitability and is a tool for the study of cortical plasticity. At stimulus intensities greater than the motor threshold (MT), high-frequency (above $1 \mathrm{~Hz}$ ) rTMS increases cortical excitability ${ }^{6,7}$, whereas low-frequency

\footnotetext{
Laboratório de Neurociências e Comportamento, Departamento de Ciências Fisiológicas, Instituto de Ciências Biológicas, Universidade de Brasília, Brasília DF, Brasil (UnB): ${ }^{1}$ Médico Neurologista, PhD, Unidade de Distúrbios do Movimento, Hospital de Base do Distrito Federal, Brasília, DF, Brasil e Pesquisador adjunto do Laboratório de Neurociências e Comportamento - UnB; ${ }^{2}$ Médico Neurologista, Professor, PhD, Laboratório de Neurociências e Comportamento - UnB; ${ }^{3}$ Acadêmico de Medicina, Programa de Iniciação Científica - UnB; ${ }^{4}$ Professor Titular, PhD, Laboratório de Neurociências e Comportamento - UnB.
}

Received 9 November 2006, received in final form 14 February 2007. Accepted 10 April 2007. 
(1 Hz or less) rTMS decreases it ${ }^{8,9}$. Circuits of the human motor cortex can be activated non-invasively by $\mathrm{TMS}^{10}$, and because the excitability of neural circuits in the cerebral cortex is not static, rTMS can produce changes in neurotransmission that outlast the period of stimulation?.

This report presents a case of improvement in cervical dystonia symptoms following 5 consecutive days of rTMS.

\section{CASE}

A 37-year-old right-handed man had primary segmental dystonia (cervical dystonia and writer's cramp in the right hand) for 2 years. His cervical dystonia consisted of involuntary twisting and cervical spasms, in a no-no head rotation, worst in lateral and dorsal decubitus and with right sternocleidomastoideus muscle hypertrophy. EMG studies showed co-contraction of the trapezius muscle and, in dorsal decubitus, rhythmic alternate discharge $(3 \mathrm{~Hz})$ of both sternocleidomastoideus muscles, with greater activity on the right. Recent MRI showed no abnormal findings. The patient was not in treatment with botulinum toxin or any other medication for 5 months.

The patient underwent rTMS following a protocol described by Lefaucher et al. ${ }^{11}$. The stimulus parameters were: coil positioned over the left premotor cortex $(2.5 \mathrm{~cm}$ anterior to the optimal scalp position for activation of the first dorsal interosseus muscle), 1200 pulses at a frequency of $1 \mathrm{~Hz}$ (i.e., a total of 20 minutes), with an intensity of $90 \%$ of the motor threshold (MT), in a total of 5 consecutive daily sessions, using an eight-shaped coil connected to a Dantec ${ }^{\circledast}$ Maglite stimulator, approved by the FDA (approval \# K931923) in 1993. No side effects were observed during the stimulation period.

The patient was evaluated before the first rTMS session, immediately after the last rTMS session, and one and four months after rTMS, using the Burke, Fahn and Marsden (BFM) rating scale ${ }^{12}$, which includes a movement scale, based on examination of the patient (maximum score: 128). Treatment efficacy was assessed by a global improvement scale $(0$, meaning no effect; 1 , mild effect but no improvement in function; 2 , moderate improvement, but no change in functional disability; 3 , moderate improvement in severity and function; 4, marked improvement in severity and function). The patient gave written informed consent prior to the study and the protocol was approved by the Ethics Committee of the Health Sciences Faculty, University of Brasília.

A substantial clinical improvement, sustained for 4 months, was observed, especially at the cervical region. The patient reported, at the end of the first week, a recovery of the capacity of remaining on lateral decubitus (without any abnormal movement), a decrease in the daily frequency of cervical spasms and improvement in the quality of his sleep, but the most striking effect was a decrease of cervical spasms at rest. Decreased hypertrophy of the sternocleidomastoideus muscle was clinically noted 1 month after the last session. The absolute value of the BFM scale was re- duced from 9 to 4 on the fifth day of stimulation, and this value was kept unchanged for 4 months, with a decrease of $50 \%$ in the neck subset. The global improvement scale showed a moderate improvement in severity and function (score 3) that lasted for 4 months. There was no effect on writer's cramp symptoms.

\section{DISCUSSION}

This case report shows that low-frequency rTMS of the premotor cortex can reduce cervical spasms, at least transiently, in a patient with a severe form of segmental dystonia. Unexpectedly, the clinical improvement was limited to torticollis, without effect over his writer's cramp. As a result, the scores of the BFM rating scale were not significantly changed. However, the neck subset of the scale had a meaningful improvement ( $50 \%$ decrease). This scale was originally intended for assessment of primary torsion dystonias and the scores can be less meaningful in the assessment of secondary and focal dystonias $^{12}$. With the present results, two interesting issues arise: 1 . why was there a bilateral response of cervical dystonia symptoms to unilateral rTMS? 2. why was there an absence of response of the patient's writer's cramp?

Low-frequency stimulation of the premotor cortex at subthreshold stimulus intensity was shown to be able to reduce primary motor cortex excitability in healthy subjects ${ }^{13,14}$. This result was found to depend on the frequency and intensity of rTMS stimuli applied to the premotor target: for instance, 1 and 5 $\mathrm{Hz}$ premotor rTMS induced opposite effects on cortical excitability ${ }^{15}$. Low-frequency rTMS over the left dorsal premotor cortex led to a sustained bilateral decrease in neuronal activity in prefrontal, premotor and primary motor cortical areas, as well as in the left putamen ${ }^{16}$. These changes were more striking in patients with primary focal dystonia than in controls. Other functional imaging and neurophysiologic studies showed that bilateral changes in interconnected cortical areas can result from unilateral application of TMMS $^{17,18}$. Repeated sessions of rTMS could amplify and prolong these effects on motor cortex excitability to such an extent as to reach clinical relevance. All these observations are strong evidence for the potential for premotor cortex stimulation in decreasing primary motor cortex activity. They are also consistent with the results of our current study, which showed that cervical dystonic symptoms, that are commonly present bilaterally, can be relieved by low frequency premotor rTMS applied unilaterally.

Another advantage of low-frequency rTMS is that it has not been reported to induce seizures, as can 
happen with high-frequency stimuli ${ }^{19}$. The only significant adverse effect that may be ascribed to lowfrequency rTMS is transient mild headache. Auditory loss, due to the loud "clicks" produced by the TMS coil, could be produced in rabbits ${ }^{20}$, but have not been confirmed in humans ${ }^{21}$, probably because all studies are now done with the use of ear-plugs.

The reason why there was no improvement in the patient's writer's cramp may have to do with the precise somatotopy of distal versus proximal movements in the premotor cortex, as proposed by Lefaucheur ${ }^{11}$ : according to this author, areas concerned with distal movements are more laterally and ventrally located in the premotor cortex, whereas those subserving proximal movements are mainly over the dorsal premotor cortex ${ }^{22}$ and were the main target of our stimuli in this study.

The clinical improvement induced by low frequency premotor rTMS in this case was stable, lasting many days. However, the current results were obtained in a single case without control by sham stimulation, and the contribution of a placebo effect cannot be ruled out. Therefore, these results need to be confirmed in larger, placebo-controlled series of dystonic patients. In addition, various targets in lateral or medial parts of the premotor cortex have to be compared.

\section{REFERENCES}

1. Chen R, Wassermann EM, Canos M, Hallett M. Impaired inhibition in writer's cramp during voluntary muscle activation. Neurology 1997;49:1054-1059.

2. Ikoma K, Samii A, Mercuri B, Wassermann EM, Hallett M. Abnormal cortical motor excitability in dystonia. Neurology 1996;46:1371-1376.

3. Ridding MC, Sheean G, Rothwell JC, Inzelberg R, Kujirai T. Changes in the balance between motor cortical excitation and inhibition in focal, task specific dystonia. J Neurol Neurosurg Psychiatry 1995;59: 493-498.

4. Allam N, Fonte-Boa PMO, Tomaz CAB, Brasil-Neto JP. Lack of effect of botulinum toxin on cortical excitability in patients with cranial dystonia. Clin Neuropharmacol 2005;28:1-5.
5. Levy LM, Hallett M. Impaired brain GABA in focal dystonia. Ann Neurol 2002;51:93-101.

6. Pascual-Leone A, Tormos JM, Keenan J, Tarazona F, Canete C, Catala MD. Study and modulation of human cortical excitability with transcranial magnetic stimulation. J Clin Neurophysiol 1998;15:333-343.

7. Berardelli A, Inghilleri M, Rothwell JC, et al. Facilitation of muscle evoked responses after repetitive cortical stimulation in man. Exp Brain Res 1998;122:79-84.

8. Muellbacher W, Ziemann U, Boroojerdi B, Hallett M. Effects of low frequency transcranial magnetic stimulation on motor excitability and basic motor behavior. Clin Neurophysiol 2000;111:1002-1007.

9. Maeda F, Keenan JP, Tormos JM, Topka H, Pascual-Leone A. Modulation of corticospinal excitability by repetitive transcranial magnetic stimulation. Clin Neurophysiol 2000;111:800-805.

10. Wassermann EM. Risk and safety of repetitive transcranial magnetic stimulation: report and suggested guidelines from the International Workshop on the Safety of Repetitive Transcranial Magnetic Stimulation, June 5-7, 1996. Electroenceph Clin Neurophysiol 1998;108:1-16.

11. Lefaucheur JP, Fenelon G, Menard-Lefaucheur I, Wendling S, Nguyen JP. Low-frequency repetitive TMS of premotor cortex can reduce painful axial spasms in generalized secondary dystonia: a pilot study of three patients. Neurophysiol Clin 2004;34:141-145.

12. Burke RE, Fahn S, Marsden CD, Bressman SB, Moskowitz C, Friedman J. Validity and reliability of a rating scale for the primary torsion dystonias. Neurology 1985;35:73-77.

13. Gerschlager W, Siebner HR, Rothwell JC. Decreased corticospinal excitability after subthreshold $1 \mathrm{~Hz}$ rTMS over lateral premotor cortex. Neurology 2001;57:449-455.

14. Munchau A, Bloem BR, Irlbacher K, Trimble MR, Rothwell JC. Functional connectivity of human premotor and motor cortex explored with repetitive transcranial magnetic stimulation. J Neurosci 2002;22: 554-561.

15. Rizzo V, Siebner HR, Modugno N, et al. Shaping the excitability of human motor cortex with premotor rTMS. J Physiol (London) 2004;554:483-495.

16. Siebner HR, Filipovic SR, Rowe JB, et al. Patients with focal arm dystonia have increased sensitivity to slow-frequency repetitive TMS of the dorsal premotor cortex. Brain 2003;126:2710-2725.

17. Fox $\mathrm{P}$, Ingham R, George MS, et al. Imaging human intra-cerebral connectivity by PET during TMS. NeuroReport 1997;8:2787-2791.

18. Wassermann EM, Wedegaertner FR, Ziemann U, George MS, Chen R. Crossed reduction of human motor cortex excitability by $1-\mathrm{Hz}$ transcranial magnetic stimulation. Neurosci Lett 1998;250:141-144.

19. Pascual-Leone A, Valls-Sole J, Brasil-Neto JP, Cohen LG, Hallet M. Seizure induction and transcranial magnetic stimulation. Lancet 1992;339:997.

20. Counter SA, Borg E, Lofqvist L. Acoustic trauma in extracranial magnetic brain stimulation. Electroencephalogr Clin Neurophysiol 1991;78:173-184.

21. Pascual-Leone A, Cohen LG, Shotland LI, et al. No evidence of hearing loss in humans due to transcranial magnetic stimulation. Neurology 1992;42:647-651.

22. Rizzolatti G, Luppino G, Matelli M. The organization of the cortical motor system: new concepts. Electroencephalogr Clin Neurophysiol 1998;106:283-296. 